\title{
Dynamics of Different Sulfur Forms in Natural Waters and Their Influence on the Redox State
}

\author{
Gheorghe Duca $^{1,}$, , Vladislav Blonschi ${ }^{2}$, Viorica Gladchi' ${ }^{2}$, Sergey $\operatorname{Travin}^{3}$ \\ ${ }^{1}$ Research Centre of Physical and Inorganic Chemistry, Institute of Chemistry, Chisinau, Republic of Moldova \\ ${ }^{2}$ Department of Industrial and Ecological Chemistry, Moldova State University, Chisinau, Republic of Moldova \\ ${ }^{3}$ Department of Dynamics of Chemical and Biological Processes, Semenov Federal Research Center for Chemical Physics of the Russian \\ Academy of Sciences, Moscow, Russian Federation
}

\section{Email address:}

ggduca@gmail.com (G. Duca), blonschivlad@mail.ru (V. Blonschi), vgladchi@yahoo.com (V. Gladchi), travinso@yandex.ru (S. Travin) ${ }^{*}$ Corresponding author

\section{To cite this article:}

Gheorghe Duca, Vladislav Blonschi, Viorica Gladchi, Sergey Travin. Dynamics of Different Sulfur Forms in Natural Waters and Their Influence on the Redox State. American Journal of Physical Chemistry. Vol. 9, No. 3, 2020, pp. 52-61. doi: 10.11648/j.ajpc.20200903.12

Received: July 16, 2020; Accepted: July 31, 2020; Published: August 19, 2020

\begin{abstract}
Sulfur-containing substances with reducing properties in natural water bodies are partners in the reactions with active oxygen forms (ROS) and so are their specific antipodes. The ratio of counterflows of an oxidizer and a reducing agent sets the redox potential of the aquatic environment, is responsible for its self-purification and ultimately forms the quality of water as a habitat. At the same time, data on the formation and destruction channels of substances with the reduced sulfhydryl groups and correlation dependences of their quantity with regard to the other components' concentrations in natural aquatic environment are fragmentary and insufficient. During the years 2015-2019, four water bodies, two lotic systems and two lentic ones were monitored. Thiols and sulfates were monitored, and it was found that in all the monitored aquatic systems the thiols content is subject to seasonal variation; therefore, its provenance is predominantly natural. To elucidate the seasonal dynamics of different sulfur forms in natural waters, the Pearson linear correlation coefficient was calculated and a positive summer correlation was attested related to the maximal biological activity. This proves that sulfate ions are used by hydrobionts as a source of sulfur for the synthesis of organic compounds, including thiols. In spring and autumn, the calculated coefficients have negative values, which denotes the dominance of chemical oxidation of the organic compounds with sulfur. These are periods with minimal biological activity. It was shown that out of two studied thiols, cysteine and glutathione, only the first one has shown the toxicity with regard to cyanobacteria.
\end{abstract}

Keywords: Monitoring, Redox Processes, Thiols, Sulfates, Cyanobacteria

\section{Introduction}

The ecological status of aquatic systems has become a key topic of numerous studies in recent decades, due to the increased anthropogenic impact on the environment. In our previous publication we have analyzed in detail the role of hydrogen peroxide in oxidation reactions occurring in natural waters [1]. Although the main source of oxidative equivalents (i.e., electron acceptor) is molecular oxygen present everywhere, its involvement in the redox turnover is only possible with the participation of the so-called Reactive Oxygen Species (ROS), hydrogen peroxide being the most well-known and significant of them.
But, if some substances actively consume electrons, there must also be their partners who supply these electrons. Of course, any organic substances (total organic carbon, TOC) are subjects to redox transformations in the course of radical self-purification processes in natural waters. However, due to the initial chemical stability (low reactivity), they are not responsible for the redox state formation of the aquatic environment.

It was noted, that the natural water quality formation as a habitat for hydrobionts is determined by its redox state, being regulated by the counter-flows ratio of hydrogen peroxide and some unidentified reducing agent production [2].

Given that natural waters are open heterogeneous system, exchanging with substances and energy with neighboring 
ecosystems, they can be presented as an open chemical reactor (Figure 1), in which the redox processes continuously take place reaching a dynamic balance between the flows of oxidant ( $\mathrm{W} \_$ox $_{\text {) }}$ and reducer $\left(\mathrm{W}_{\text {_red }}\right)$.

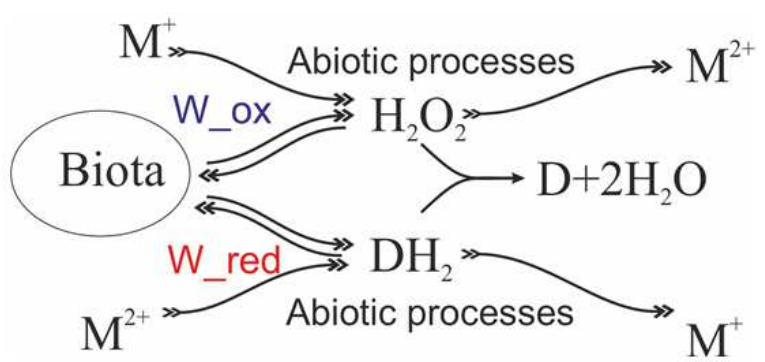

Figure 1. Phisyco-bio-chemical model of self-purification and the redox state formation of water environment.

Depending on the dominance of one or another component, the redox state can be either oxidative (when $[\mathrm{Ox}]>[\mathrm{Red}]$ ) or reductive (that is $[\mathrm{Ox}]<[\mathrm{Red}]$ ). In the first case the medium is characterized by the presence of a measurable amount of $\mathrm{H}_{2} \mathrm{O}_{2}$, which in turn ensures the development of radical selfpurification processes due to the radicals $(\mathrm{OH})$ generation [1]. In the contrary case, $\mathrm{H}_{2} \mathrm{O}_{2}$ is not only absent in the medium, but there is a certain amount of reducing substances titrated with hydrogen peroxide.

Initially, it was tacitly asumed that the redox state of the open system medium is dictated by the counter-flows ratio of the oxidizing and reducing agents. If the reducing generation stream dominates (W_red $>$ W_ox), then the state of the environment will be also reducing, and vice versa.

In fact, kinetic analysis of processes in an open system shows that the redox state is determined not only and not so much by the flow rates, but by the rate constants of substances degradation in natural conditions. Indeed, it is extremely difficult to imagine an artificially contrived situation in which counter-flows are balanced with the highest accuracy. In real conditions, there is almost guaranteed bias in one or another direction. And if there were no alternative channels to regulate the concentrations, any fluctuation would tip the system to one of the extremes.

It is known, however, that all the natural systems are subjects to the homeostasis principle and very stubbornly resist to any attempt to bring them out of a stable stationary state. Everything becomes clear and logical within the framework of the following scheme:

$$
\begin{aligned}
W_{\text {Red }} & \rightarrow \text { Red } \\
W_{O x} & \rightarrow \text { Ox } \\
\text { Red } & \rightarrow \text { destruction, } k_{1} \\
\text { Ox } & \rightarrow \text { destruction }, k_{2} \\
\text { Ox }+ \text { Red } & \rightarrow \text { mutual loss }, k_{3}
\end{aligned}
$$

If we assume that $\frac{W_{R e d}}{W_{O x}}=\alpha \neq 1$, then steady-state concentrations will be determined by the equations:

$$
\begin{gathered}
\frac{d[\text { Red }]}{d t}=\alpha W-k_{1}[\text { Red }]-k_{3}[\text { Red }][O x] \\
\frac{d[O x]}{d t}=W-k_{2}[O x]-k_{3}[\text { Red }][O x]
\end{gathered}
$$

Substracting one equation from another (for the sake to neglect term $\left.k_{3}[\operatorname{Red}][O x]\right)$ and claiming $[O x] \approx[\operatorname{Red}]$, one can get $[O x] \approx[\operatorname{Red}] \approx(\alpha-1) W /\left(k_{2}-k_{1}\right)$.

So the dominance of oxidant flow $(\alpha<1)$ can be easily overturned by the bigger rate constant of its self-destruction. It seems that this is the case of what happens with hydrogen peroxide.

As an example we can demonstrate a model kinetical curves for the scheme (1) - (5) Figure 2.

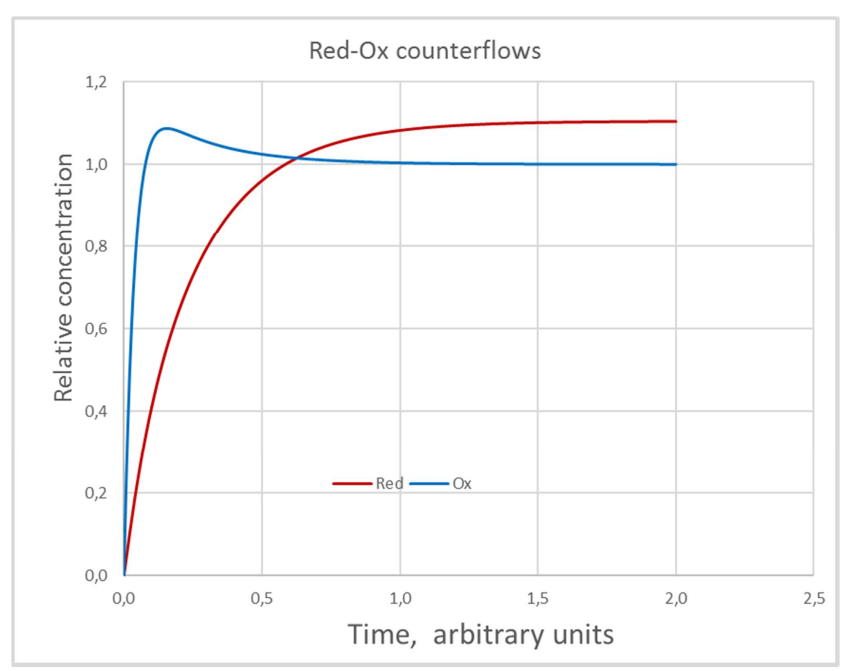

Figure 2. Modelling of scheme (1) - (5) with parameters: $W_{\text {Red }}=5$, $W_{O x}=31, k_{1}=0.02, k_{2}=26, k_{3}=4.5$.

The oxidant flow is six times higher, than that of the reducer, due to high self-destruction rate constant (typical for hydrogen peroxide); then the relaxation system comes to the reduced state.

$$
\varphi=\varphi_{O x}^{0}-\varphi_{R e d}^{0}+\frac{R T}{n F} \ln \left(\frac{[O x]}{[R e d]}\right)
$$

Finally, the redox potential is determined by the ratio of steady-state concentrations (not the flows!) of oxidant and reductant. If these concentrations are comparable, the ratio under logarithms becomes unity, and logarithm (second term) in the Nernst equation (8) is negligible. Thus, the redox potential only depends of the redox-participants' chemical nature, namely, glutathione and hydrogen peroxide. In this case it is constant and the system is very stable.

At the same time, a hypothesis was expressed indirectly, that thiol and sulfhydryl compounds are most likely those substances of reducing nature. There is now a growing body of evidence suggesting that glutathione is the main natural counterpart to hydrogen peroxide.

In the Earth's crust sulfur ranks $2^{\text {nd }}$ after oxygen, so that its amount is enough to bind into sulfides the entire mass of 19 chalcophile elements (more prone to the formation of sulfides 
than oxides). In the waters of the World Ocean sulfur is present in the form of sulfate ions - an average of $0.09 \%$ per $\mathrm{S}$, taking $2^{\text {nd }}$ place after chloride ions. In terms of content in living organisms sulfur occupies the $10^{\text {th }}$ place among the most important biogenic elements with an average content of $0.05 \%$.

Thiol-containing compounds play an important role in biological systems protection from the oxidative damage [3, 4]. Glutathione (GSH) is the most widespread cytosol thiol and belongs to endogenous bioantioxidants synthesized directly in living organisms. GSH interacts with hydroxyl radicals, restores hydrogen peroxide, hydroperoxides, disulfide bonds -S-S- and prevents oxidation of proteins [5, 6]. The concentration of GSH in biological tissues is $0.1-10$ mmol 1-1, which is significantly higher than the concentrations of other potential bioantioxidants.

Glutathione is a tripeptide formed by residues of three amino acids: glutamic acid, cysteine and glycine [7, 8]. It is the most widely represented non-protein thiol in most aerobic species, having intracellular concentration from 0.5 to 10 $\mathrm{mmol} / \mathrm{dm}^{3}$. In contrast, its extracellular concentration is usually 3-4 orders of magnitude lower. Glutathione in the cell is found as the mixed disulfides (mainly GS-S-proteins), disulfides (GSSG) and thioesters. Under the normal physiological conditions, about $98 \%$ of glutathione is in the reduced thiol form GSH.

In cells GSH is mainly present in the reduced form, which is oxidized to disulfide by ROS. The ratio of reduced and oxidized forms of glutathione ([GSH]/[GSSG]) in the cell is one of the most important parameters that shows the level of oxidative stress. Oxidative stress is characterized by the increased content of ROS and reflects an imbalance between the rates of ROS formation and their utilization [9-11].

It is believed that it is possible to evaluate the functional state of antioxidant protection by the ratio between the concentration of thiol and disulfide groups in the biosubstrate and use this index as an integral test to assess the nonspecific resistance of the body [12].

The metabolic studies of sulfur containing species in natural waters have been branched into two major directions, which are as follows: (1) the global biogeochemical cycle of volatile sulfur species, such as dimethyl sulfide (DMS), carbonyl sulfide (OCS), and related compounds and (2) the detoxification properties of thiolic compounds, such as glutathione, cysteine (Cys), and sulfide, to ameliorate the oxidative stress caused by trace metals, radicals, and other xenobiotic compounds [13]. At the molecular level these studies are related to synthesis and transformation of amino acids in living organisms.

The factors influencing the presence of thiol glutathione (GSH) in estuarine waters were investigated in [14]. This study had addressed the thiol phase-association, the biological thiols release from algal cultures, and the role of copper in both thiol release and preservation. The measurements in three diverse estuaries in the continental United States (San Diego Bay, Cape Fear Estuary, and Norfolk Estuary) show that dissolved GSH, present at subnanomolar levels, is preferentially partitioned into the ultra- filtrate fraction $(<1 \mathrm{kDa})$ in comparison with the dissolved organic carbon (DOC). Concentrations of GSH were generally increased with increases in total copper $(\mathrm{Cu})$ levels, although the large variability was observed among the estuaries. In 30-h exposure experiments, release of dissolved GSH from the diatom Thalassiosira weissflogii into the organic ligand-free experimental media was a strong function of added $\mathrm{Cu}$ concentration.

The released GSH increased from about 0.02 to 0.27 $\mathrm{fmol} / \mathrm{cell}$ as $\mathrm{Cu}$ was increased from the background level 0.5 $\mathrm{nM}$ to $310 \mathrm{nM}$ in the modified Aquil media. Nevertheless, considered in total, the data from the pooled sites do not show clear relationships between normalized GSH concentration and either $\mathrm{Cu}$ or DOC concentration. However, some trends are apparent in data from individual sites e.g., positive correlation of GSH to $\mathrm{Cu}$ and negative relation of GSH to DOC.

The task of our research was to obtain the additional information on the impact of various factors in the aquatic environment on glutathione concentration. From a physicochemical point of view, natural waters represent an open photochemical, catalytic system with several components and phases [15]. Thanks to all the environmental factors, including the activity of hydrobionts, the chemical composition of natural waters has a dynamic character characterized by the flows of the redox equivalents formation and decomposition $[16,17]$.

The balance between the oxidative and reducing equivalents is characterized by the parameter called the redox state [18]. The main oxidants in natural waters are dissolved oxygen and hydrogen peroxide, which over several decades have been studied in detail $[19,20]$. At present, the research in the field of physical and ecological chemistry demonstrates that the reducing equivalents are very diverse both in terms of their origin sources and chemical nature.

A class of reducing compounds, present in the composition of natural waters, are thiols, with the general formula R-SH, fulfilling the various functions in biogeochemical systems [21]. The sources of origin are determined by the biochemical processes in which they are involved. Thus, thiols, especially cysteine, participate in the synthesis of proteins, glutathione, phytochelatin (PC), coenzyme A (CoA), and in some organisms Cys also plays the role of detoxifier [22, 23]. The tripeptide $\gamma$-L-glutamyl-L-cysteinylglycine is the most abundant non-protein thiol in eukaryotic and many prokaryotic cells [24]. GSH has many roles in living cells, including the heavy metals and other species detoxifier, "deposit" of Cys, precursor in PC synthesis, which is due to the balance between the two forms appears in the reduced (GSH) or oxidized (GSSG) state [25].

Most hydrobionts synthesize PC as a heavy metal detoxifier, with the secretion of complex compounds formed in the aquatic environment. However, according to the research, a number of thiols, such as Cys, GSH, arginylcysteine $(\mathrm{RC}), \gamma$-glutamylcysteine $(\gamma \mathrm{EC})$, have been found in various natural water sources, both with high mineralization (salt water) and low mineralization (fresh water). The presence of a wide range of thiols in the environment is explained by the fact that the biochemical 
mechanisms of hydrobionts detoxification occur not only in vivo, but also in vitro. In other words, some hydrobionts remove thiols from the environment in response to the presence of various toxins, such as heavy metals [26]. Some works also reveal the insufficiently studied in vitro biochemical mechanisms in which thiols are used to transport the heavy metal ions, regulate their reactivity and bioavailability in the aquatic environment.

Various sources of sulfur are required for the normal functioning of all living organisms, regardless of species. The limiting factor of heterotrophic aquatic organisms' living activity is the concentration of sulfur compounds in the reduced form ( $\left.\mathrm{R}-\mathrm{SH}, \mathrm{H}_{2} \mathrm{~S}\right)$, which sources are the redox chemical processes and metabolic processes in hydrobionts, especially autotrophic ones. Therefore, autotrophic organisms, such as cyanobacteria, use sulfates as sources of sulfur for the synthesis of necessary organic compounds [27]. In case of strongly mineralized waters, the sulfate content can be considered constant, thanks to the high concentrations (approx. $29 \mathrm{mM}$ ). Although, in waters with low mineralization, the content of sulfates can become a limiting factor in the growth and development of hydrobionts [28]. In the case of cyanobacteria, autotrophic organisms that consume large amounts of sulfates for thiol synthesis used in the inhibition of reactive oxygen species (ROS), resulting from the photosynthesis process, seasonal variations in the sulfates' amounts can become a major limiting factor.

Thus, the purpose of this research is to establish correlations between sulfur compounds with different oxidation degrees, in slow and lotic natural water bodies and to establish ranges of maximum allowable concentrations of thiols, at which no severely disrupts of cyanobacteria activity occurs.

\section{Experimental Part}

\subsection{Water Sampling}

During the years 2015-2019, four water bodies within the Nistru river basin were monitored: Nistru river (in the portion of Vadul lui Voda village); Raut river (a tributary of the Nistru, near the Ustia village); Ghidighici lake (built along the Bic river near Vatra village); Danceni lake (built on the course of the Isnovat river, near Danceni village).

Water samples were taken seasonally, with an intensity of 5-7 times a year. In large water basins, samples were collected to the depth of $0.5 \mathrm{~m}$, and from the Raut river, they were collected from the central part [29].

\subsection{Determination of Thiol and Sulfate Content}

The content of thiol compounds was determined using the Ellman spectrophotometric method [30]. The sensitivity was ensured due to the high value of the molar extinction coefficient of the reaction product, the 2-nitro-5-thiobenzoate anion $\left(\mathrm{TNB}^{2-}\right)$ [31].

The sulfate content was determined by the turbidimetric method, by measuring the absorbance at the $400 \mathrm{~nm}$ wavelength.

\subsection{Determination of Biomass, Proteins and Phycobilins Content}

Determinations of the Arthrospira platensis species were performed in accordance to method described in [32].

The biomass content was determined in the culture fluid at $620 \mathrm{~nm}$ optical density, the wavelength specific to phycobilin pigments present in living culture.

The protein content was determined by the Lowry method. The formed chromophore complex was detected by reduction with Folin-Ciocalteu reagent.

For the determination of phycobilins, spirulina biomass destroyed by the technique of repeated freezing/ thawing in hydric solution with a biomass concentration of $10 \mathrm{mg} / \mathrm{cm}^{3}$ was used. The absorbance was measured at $620 \mathrm{~nm}$ for cphycocyanin and at $650 \mathrm{~nm}$ for allo-phycocyanin. The pigment content was determined based on the molar extinction coefficient for c-phycocyanin of $1.54 \cdot 10^{6} \mathrm{M}^{-1} \mathrm{~cm}^{-1}$ and for allo-phycocyanin of $0.7 \cdot 10^{6} \mathrm{M}^{-1} \mathrm{~cm}^{-1}$. The values obtained are expressed in $\%$ biomass.

\section{Results and Discussion}

During the years 2015-2019, four water bodies were monitored, making part of the Nistru river basin, of which two are lotic systems (Nistru and Raut river) and two lentic (Ghidighici and Danceni lakes). The thiols content was monitored and the detected concentration was $10^{-6}-10^{-5} \mathrm{~mol} / \mathrm{L}$ in all water bodies (Table 1 ). The highest concentrations were found in the waters of Ichel river, the multiannual average being $10,145 \cdot 10^{-6} \mathrm{~mol} / \mathrm{L}$. In the waters of accumulation lakes and in the Nistru river, the detected concentrations had lower values (Table 1).

Table 1. Annual averages of thiol compounds determined in monitored water bodies.

\begin{tabular}{|c|c|c|c|c|c|c|}
\hline \multirow{2}{*}{ Catchment } & \multicolumn{6}{|c|}{$[\mathrm{R}-\mathrm{SH}] \cdot 10^{6}(\mathrm{~mol} / \mathrm{L})$} \\
\hline & 2015 & 2016 & 2017 & 2018 & 2019 & Multiannual average \\
\hline Nistru river & 5.88 & 2.13 & 5.19 & 4.32 & 6.15 & 4.734 \\
\hline Ghidighici lake & 7.24 & 4.11 & 4.45 & 5.57 & 5.00 & 5.274 \\
\hline Danceni lake & 8.07 & 4.14 & 5.68 & 5.02 & 6.12 & 5.804 \\
\hline
\end{tabular}

Seasonal variation of thiols was observed in the monitored aquatic objects. The maximum content was recorded in summer when the activity of hydrobionts is most intensive, followed by a decrease in concentration in autumn, when the 
activity of hydrobionts diminished. This variation indicates the predominantly natural origin of thiols in water bodies. Thus, in the Nistru river, except for 2019, the seasonal variation is well delimited (Figure 3). In the waters of Raut river, the seasonal variation was registered only in 2015, and in the other monitoring years the maximum concentration was attested in autumn, which indicates the slowdown of self-purification processes and probably the anthropogenic pollution (Figure 4).

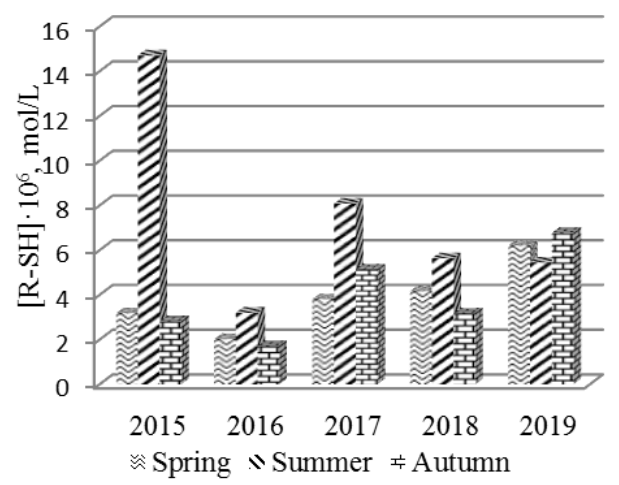

Figure 3. Seasonal variations in thiol content in the waters of the Nistru River.

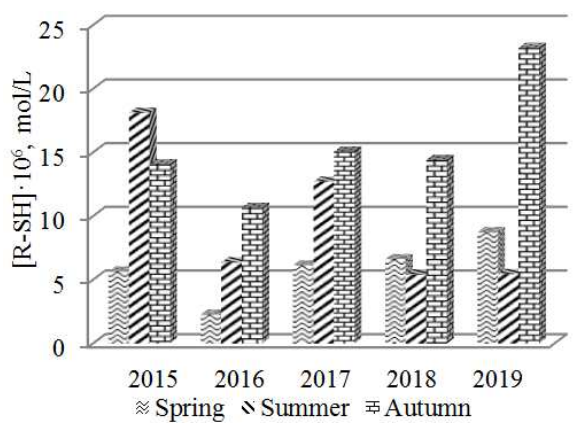

Figure 4. Seasonal variations in thiol content in the waters of the Raut River.
In the waters of Ghidighici lake only in 2017 there was no seasonal variation of thiols observed (Figure 5), and in the waters of Danceni lake during the entire monitoring period there was a seasonal variation of thiol compounds (Figure 6).

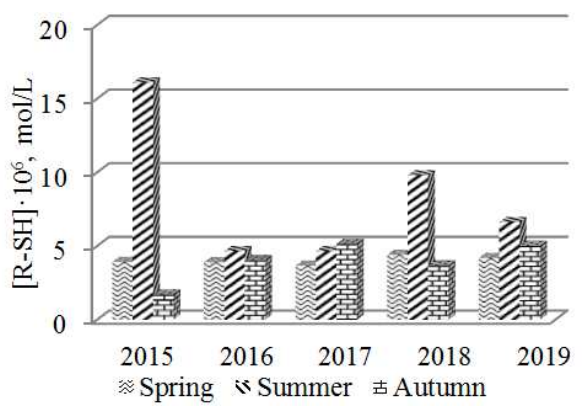

Figure 5. Seasonal variations in thiol content in the waters of the Ghidighici lake.

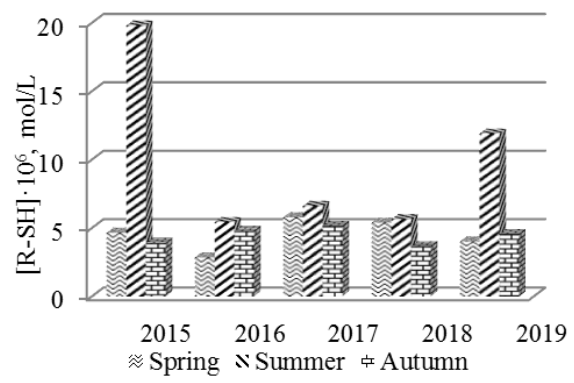

Figure 6. Seasonal variations in thiol content in the waters of the Danceni lake.

Another chemical parameter monitored was the sulfate content $\left(\mathrm{SO}_{4}{ }^{2-}\right)$. The multiannual averages of sulfate content in all water bodies were consistent with the results of previous research of these natural waters. The sulfates concentration in the waters of Nistru river was $71,303 \mathrm{mg} / \mathrm{L}$ (Table 2), similar to the value determined in the years 2003-2010 [33].

Table 2. Annual averages of sulfate content determined in the monitored water bodies.

\begin{tabular}{|c|c|c|c|c|c|c|}
\hline \multirow{2}{*}{ Catchment } & \multicolumn{6}{|c|}{$\left[\mathrm{SO}_{4}{ }^{2-}\right](\mathrm{mg} / \mathrm{L})$} \\
\hline & 2015 & 2016 & 2017 & 2018 & 2019 & Multiannual average \\
\hline Nistru river & 89.05 & 79.10 & 60.94 & 58.38 & 69.00 & 71.303 \\
\hline Raut river & 593.40 & 536.33 & 642.60 & 576.20 & 515.50 & 572.813 \\
\hline Ghidighici lake & 644.80 & 347.36 & 372.76 & 424.10 & 247.63 & 407.331 \\
\hline Danceni lake & 434.88 & 190.60 & 173.48 & 137.24 & 142.31 & 215.702 \\
\hline
\end{tabular}

The waters of Raut river are characterized by high mineralization, and the multiannual average of sulfates concentration (Table 2) indicates the dominance of this ion. According to the hydrochemical index, in the catchment near the Ustia village, the waters of Raut are of sulfate-hydrogen carbonate type [34]. The sulfate ion is dominant in another monitored aquatic system. Thus, the waters of the Ghidighici accumulation lake, located on the Bic river, according to the hydrochemical index are sulfate-hydrogen carbonates. The waters of Danceni lake, located on the Isnovat river, are of hydrogen carbonate type, therefore the sulfate ion is not dominant (Table 2).

A specific of natural waters with low mineralization is the seasonal variation of the main ions, to which sulfate ions belong (Figures 7-10).

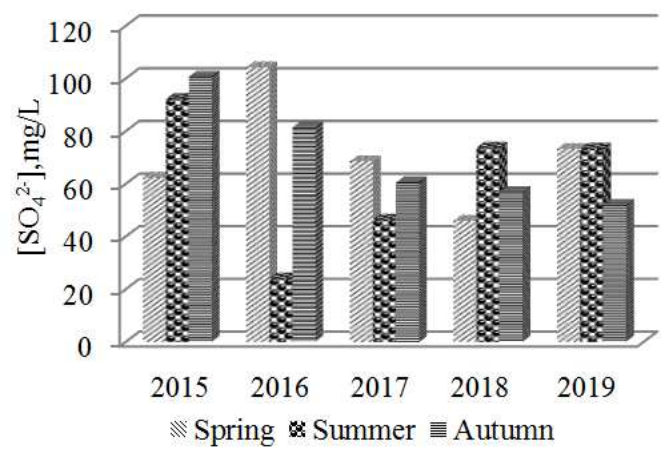

Figure 7. Seasonal variations in sulfate content in the waters of Nistru river. 


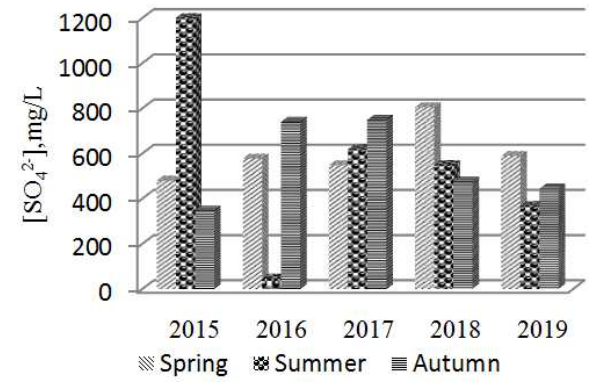

Figure 8. Seasonal variations in sulfate content in the waters of Raut river.

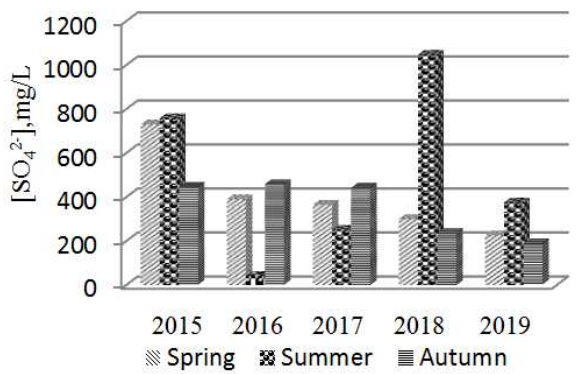

Figure 9. Seasonal variations in sulfate content in the waters of Ghidighici lake.

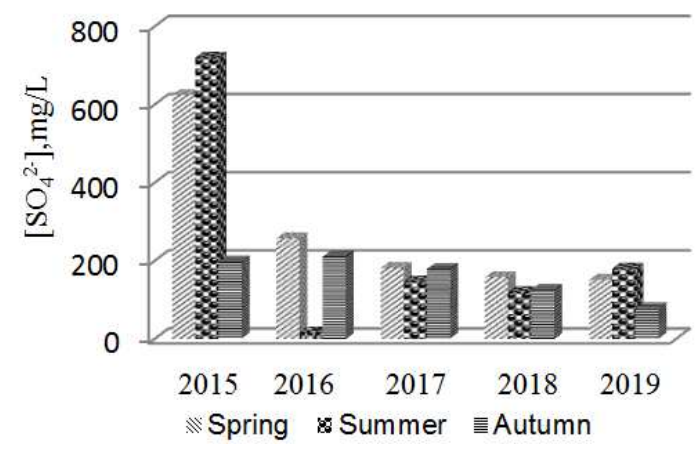

Figure 10. Seasonal variations in sulfate content in the waters of Danceni lake.

Therefore, in freshwater the content of sulfate ions can become a limiting factor for the development of hydrobionts, especially photoautotrophic ones. In order to elucidate the dynamics of different sulfur forms, the Pearson linear correlation coefficient was calculated, between the seasonal variations of the organic sulfur forms (thiols) and inorganic forms (sulfates) (Table 3).

Table 3. Pearson coefficient values calculated on the basis of seasonal variations in thiol and sulfate content.

\begin{tabular}{|c|c|c|c|}
\hline Catchment & Spring & Summer & Autumn \\
\hline Nistru river & $\begin{array}{l}-0.44 \\
\text { weak negative correlation }\end{array}$ & $\begin{array}{l}0.69 \\
\text { moderate positive correlation }\end{array}$ & $\begin{array}{l}-0.68 \\
\text { moderate negative correlation }\end{array}$ \\
\hline Raut river & $\begin{array}{l}0.19 \\
\text { very weak positive correlation }\end{array}$ & $\begin{array}{l}0.85 \\
\text { strong positive correlation }\end{array}$ & $\begin{array}{l}-0.43 \\
\text { weak negative correlation }\end{array}$ \\
\hline Ghidighici lake & $\begin{array}{l}-0.40 \\
\text { weak negative correlation }\end{array}$ & $\begin{array}{l}0.72 \\
\text { strong positive correlation }\end{array}$ & $\begin{array}{l}-0.32 \\
\text { weak negative correlation }\end{array}$ \\
\hline Danceni lake & $\begin{array}{l}-0.09 \\
\text { very weak negative correlation }\end{array}$ & $\begin{array}{l}0.95 \\
\text { positive correlation close to perfect }\end{array}$ & $\begin{array}{l}0.20 \\
\text { very weak positive correlation }\end{array}$ \\
\hline
\end{tabular}

Considering that in the summer the activity of hydrobionts is maximal, confirmed by the seasonal variations of thiols (Figures 3-6), the autotrophic aquatic organisms consume the largest amounts of ion sulfates.

The higher amounts of sulfates promote the better conditions for aquatic organisms' development, and increased amounts of the sulfur containing organic compounds (thiols). This legitimacy is confirmed by the values of the Pearson coefficient, in summer which vary from moderate to almost perfect correlations (Table 3). During the spring and autumn, the biological activity of hydrobionics is slowed down and oxidation of organic matter dominates. In the case of sulfur compounds, thiols oxidation takes place, sulfate ion being ultimate oxidation product.

Respectively, there is a negative correlation between these two forms (thiol and sulfate), i.e. with the decrease of thiol content, the concentration of sulfate ions increases. This legality is well delimited in the case of Nistru river, attesting the highest values of the correlation coefficient (Table 3 ). In the rest water bodies, the values of the Pearson coefficient indicate the weak and very weak correlations, probably because the self-purification processes are slowed down, respectively the organic matter decomposes at much lower rates. These cyclic processes of sulfur transition into the organic forms from minerals and vice versa, denote the fact that thiols could participate directly in the sulfur circuit in nature.

To better understand the physico-chemical and ecochemical processes with the participation of thiols, which take place in aquatic systems, the experiments were performed in laboratory conditions to establish the tolerance limits of hydrobionts to thiols. Aquatic organisms eliminate low molecular weight thiols in the environment in response to the risk factors, especially heavy metal ions. Therefore, under the conditions of increased toxicity, the amount of thiols can increase considerably, and this in turn can become toxic to living organisms.

Two thiols (Cys, GSH) were studied, the most abundant in both biochemical processes in vivo and the aquatic environment. The cyanobacterial species Arthrospira platensis $C N M N-C B-02$ (spirulina) was used as a typical representative of autotrophic aquatic organisms. The content of biomass, proteins and phycobilins was determined. The toxicity was only shown in the presence of Cys in the environment (Figure 11a-13a). At concentrations of $300 \mathrm{mg} / \mathrm{L}$ Cys reduces about $50 \%$ biomass (Figure 11a) and promotes the synthesis of phycobilins (Figure 13a). Glutathione did not show the increased toxicity, with the slight decrease in spirulina biomass 
(Figure 11b), total protein content regarding the biomass content (Figure 12b) and phycobilin synthesis. Thiol did not

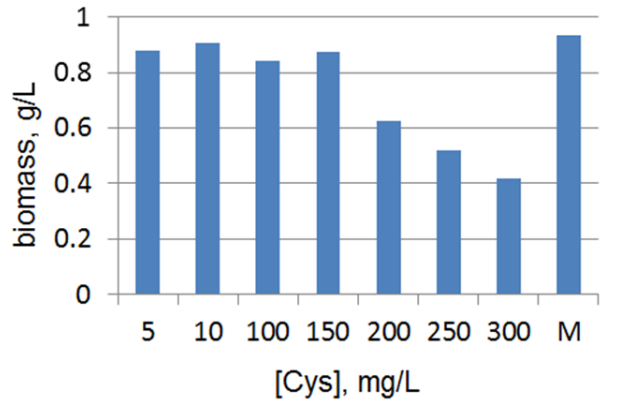

(a) show any toxic influence (Figure 13b).

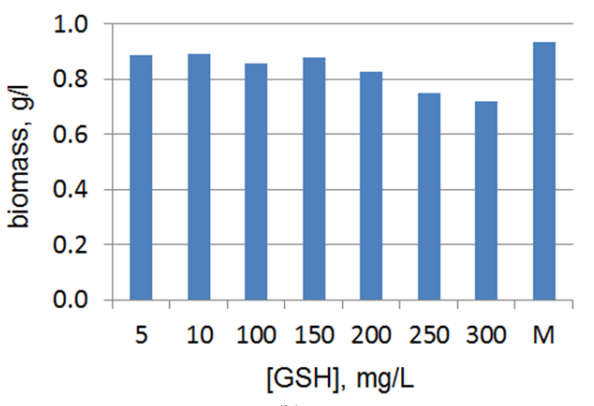

(b)

Figure 11. The variation of spirulina biomass depending on the thiol concentration (a) - cysteine, (b) - glutathione.

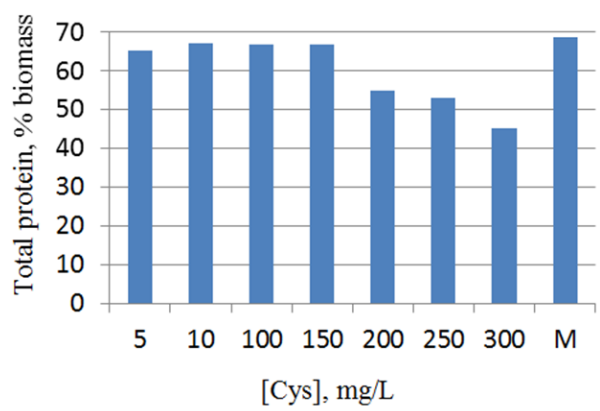

(a)

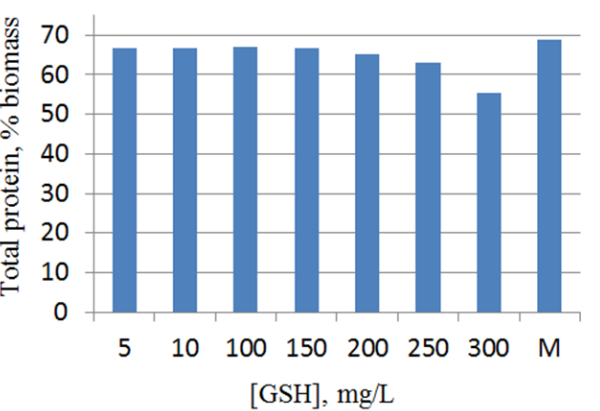

(b)

Figure 12. The variation of the protein content of the spirulina biomass depending on the thiol concentration (a) - cysteine, (b) - glutathione.

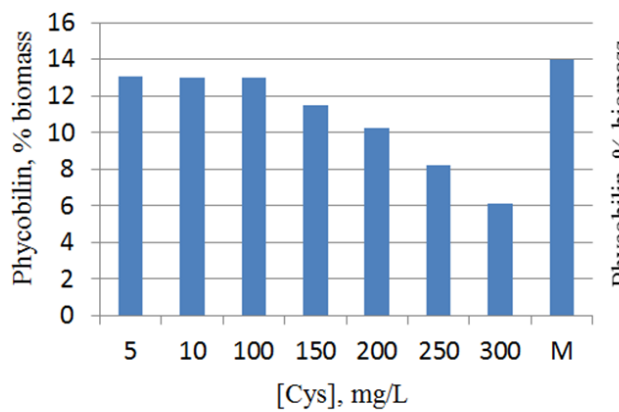

(a)

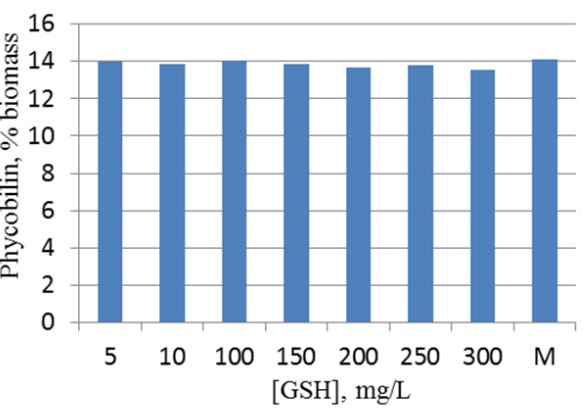

(b)

Figure 13. Variation of phycobilin content in spirulina biomass depending on thiol concentration (a) - cysteine, (b) - glutathione.

Therefore, cysteine at relatively low concentrations (300 $\mathrm{mg} / \mathrm{L}$ ) in the aquatic environment can severely disrupt spirulina activity, also altering the redox state of natural waters.

Given the fact that thiols are among the main natural substances that form the reducing component affecting the redox state of natural waters, we tried to elaborate a mathematical model to confirm the experimental data obtained and to predict the flows of thiols and sulfates in aquatic systems.

The data related to four water bodies over the 5-years period (a total of 93 observations; during the winter months no measurements were made) were applied for calculations. Each observation had three formal input parameters (place, or name of water body, month and year) and six chemical concentration parameters, five of which were considered as independent control variables (Sulfate, Phosphate, Mineralization, Water Hardness, Calcium) and the sixth was Glutathione as a function of the entire input data set. As a regression function for data analysis a square form with cross terms was used, i.e. bilinear function of the form (9).

$$
y\left(x_{1}, x_{2}, \ldots, x_{n}\right)=\alpha_{0}+\sum_{i=1}^{n} \alpha_{i} x_{i}+\sum_{i=1, j=1}^{n} \beta_{i j} x_{i} x_{j}
$$

In case of using of the whole set of eight input variables (three spatio-temporal and five concentration variables), the total number of fitting parameters in the regression analysis will be 73 (64 coefficients for second-degree members, 8 linear terms and a free term), which, in our opinion, is clearly redundant to minimize the error functionality on 93 measurements. To eliminate or reduce this contradiction, during the primary analysis the parameter of the reservoir number and the calendar year date were abandoned, since the apparent time trend was obviously absent, and the conversion of the reservoir name into digital index form was obviously arbitrary. At the same time, the number of considered months was left, because seasonal changes were obviously significant 
for the model. Thus, we have reduced the number of control parameters to 43 , of which only 25 were independent, due to the symmetry of coefficient matrix, which is quite acceptable for evaluation of the set of 93 series.

The calculation result is shown on the Figure 14. It can be seen on the qualitative level, that the more the reference value is, the higher is the calculated value. That means that some interrelation between the species takes place, but highly likely the regression equation cannot be considered as polynomial of second order one.

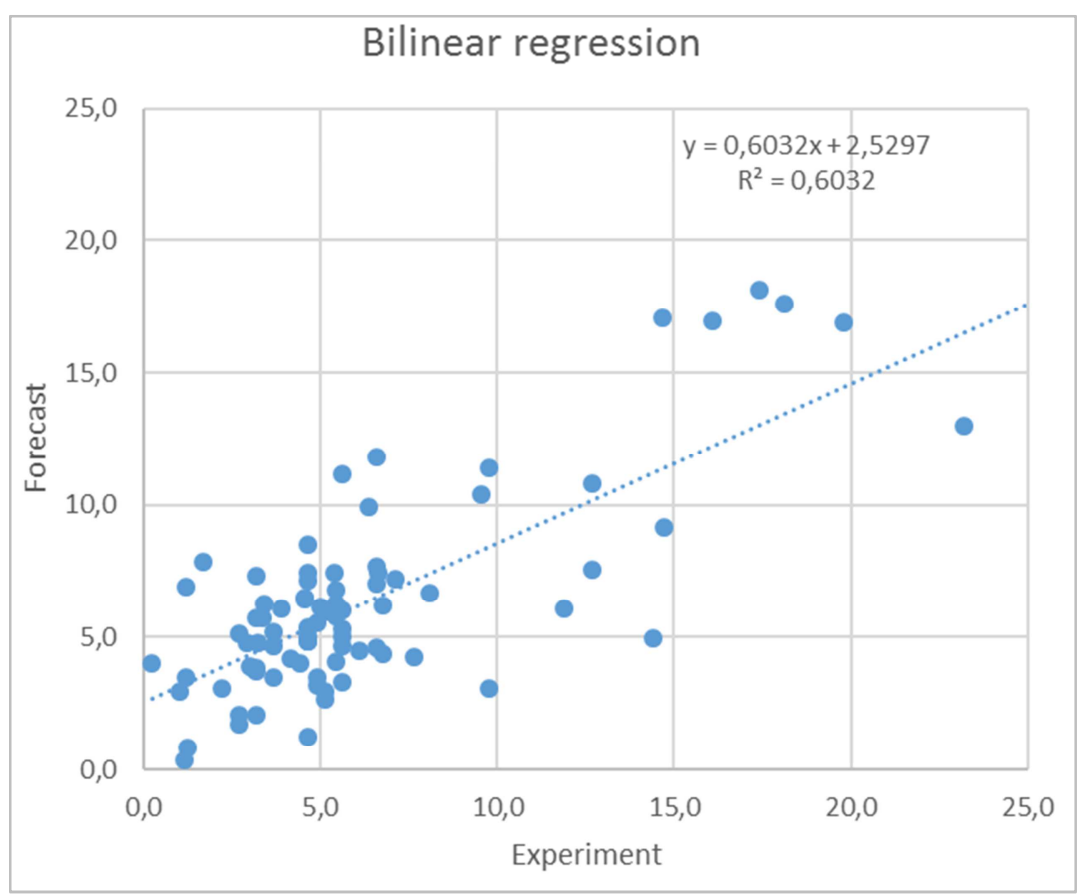

Figure 14. Interrelation between various species in bilinear regression equation (1) with six variables giving the set of 25 independent parameters.

Further on, the regularities were investigated, linking the glutathione concentration with other indicators of water systems, using a neural network. To be able to compare grams per liter with months and to ensure equal a priori importance of each, all the numerical parameters of the model were normalized, so that the whole set of values for each variable had a variation within the range from 0 to 1 .

According to the full number of control variables, we have selected a neural network with eight inputs and one output for training. Two hidden layers were sufficient to ensure the adequate setup. The neural network was trained using the algorithm of error back propagation with the self-made program developed in VBA-Excel environment.

For the sake of clarity, 2019 data were excluded from the series of data for neural network training, and then, when all weights of individual neurons were adjusted, the expected glutathione concentrations were calculated and compared with the actual ones. The results are shown on Figure 15.

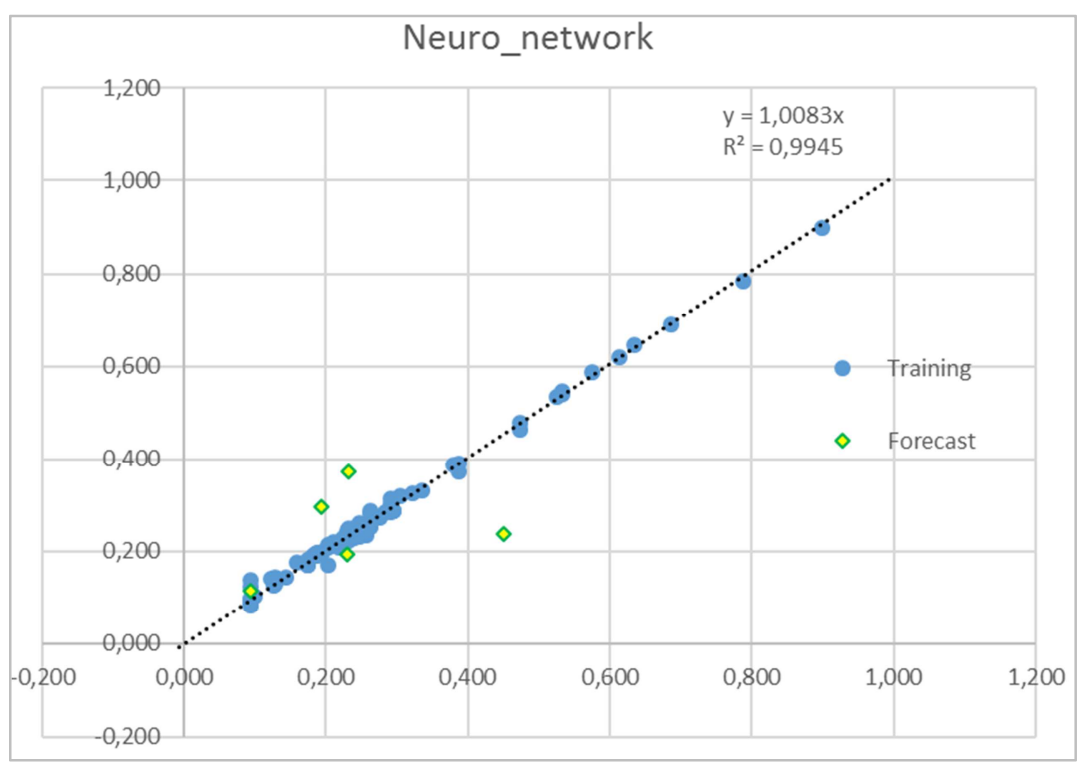

Figure 15. Forecast of glutathione concentration with trained neuro network. 
In contrast to the polynomial regression model, the trained neural network produces predictions for which the correlation coefficient $\mathrm{R}^{2}=0.9945$. The proportionality coefficient between the experimental and predicted values varies within three decimal places.

\section{Conclusions}

During 2015-2019, the content of thiol compounds in four water bodies making the part of the Nistru river basin was monitored, which falls within the range $10^{-6}-10^{-5} \mathrm{~mol} / \mathrm{L}$.

Seasonal variation of thiols was detected, which indicates their predominantly natural origin. This means that the flows of the reducers and oxidants which determine the redox state of natural waters are formed with participation of hydrogen peroxide on one hand and thiols on the other hand.

The seasonal dynamics of two sulfur forms in waters with low mineralization, thiols and sulfate ions were analyzed and a positive linear correlation was found during the summer, which indicates that with the increase of sulfate content, the thiol content increases. During the autumn and spring, the linear correlations are negative, which indicates the thiols oxidation in inorganic sulfates, along with the slowing down of biological processes in hydrobionts. These cyclic processes of sulfur transition into the organic forms from minerals and vice versa, denote that thiols could participate directly in the sulfur circuit in nature.

The toxicity of two thiols, cysteine and glutathione, with regard to cyanobacterial species Arthrospira platensis was investigated and it was found that only cysteine shows the increased toxicity. At a concentration of $300 \mathrm{mgCys} / \mathrm{L}$ there is $50 \%$ inhibition in biomass development and phycobilin synthesis. Glutathione does not show any toxicity at this concentration. The use of a neural network has shown that glutathione concentration can be predicted quantitatively based on the set of water quality indicators.

\section{References}

[1] Duca G., Travin S. // Hydrogen Peroxide: Reaction Mechanisms and Applications // American Journal of Physical Chemistry (AJPC), American Journal of Physical Chemistry. 2020, 9 (2). ISSN: 2327-2430 (Print); ISSN: 2327-2449 (Online). pp. 36-44. doi: 10.11648/j.ajpc.20200902.13.

[2] Frog B. N., Skurlatov Y. I., Stramm E. V., Vichutinskaya E. V., 2012// Effect of water-soluble compounds of reduced sulfur on the toxic properties of natural and waste waters // ISSN 1997-0935. Vestnik MGSU. 2012. № 6 p.105.

[3] Poole L. B. // Free Radical Biology and Medicine. 2015, V. 80. P. 148.

[4] Winterbourn C. C., Metodiewa D. // Free Radic. Biol. Med. 1999. V. 27. P. 322.

[5] Kheirabadi R., Izadyar M. // J. Phys. Chem. A. 2016, V. 51. № 120. P. 10108 / doi: 10.1021/acs.jpca.6b11437.

[6] Kritzinger E. C., Bauer F. F., du Toit W. J.// J. Agric.Food
Chem. 2013. V. 2. № 61. dx.doi.org/10.1021/jf303665z.

[7] Meister A. Glutathione metabolism and it's selective modification // The Journal of Biological Chemistry //1988. Vol. 263. N. 33. P. 17205-17208.

[8] Ballatori N. Glutathione mercaptides as transport forms of metals // Adv. Pharmacol. 1994. Vol. 27 P. 271-298.

[9] Sies H. Oxidative Stress. L.: Academic Press. 1985. P. 1.

[10] Sies H., Jones D. P. Encyclopedia of Stress. San Diego, CA.: Elsevier. 2007. V. 3. P. 45.

[11] Reuter S., Gupta S. C., Chaturvedi M. M., Aggarwal B. B. //Free Radic. Biol Med. 2010. V. 49. № 11. P. 1603.

[12] Kabanov A. V. // Methods for determination of thiol-disulfide equation and glutathione concentration in biological fluids // Medicine: theory and practice, special issue, Volume 4, 2019 eISSN 2658-4204.

[13] Degui Tang, Chin-Chang Hung, Kent W. Warnken, and Peter H. Santschi / The distribution of biogenic thiols in surface waters of Galveston Bay //Limnol. Oceanogr., 45 (6), 2000, 1289-1297.

[14] Degui Tang, Martin M. Shafer, Dawn A. Karner, Joel Overdier, David E. Armstrong// Factors Affecting the Presence of Dissolved Glutathione in Estuarine Waters // Vol. 38, No. 16, 2004 / Environmental Science \& Technology.

[15] Gladchi, V., Bunduchi, E., Romanciuc, L. Ecological Chemistry of the Natural Waters. In: Duca, G., Vaseashta, A. (Ed.), Handbook of Research on Emerging Developments and Environmental Impacts of Ecological Chemistry. IGI Global, 2020, pp. 197-211.

[16] Duca, G., Gladchi, V., Romanciuc, L. Processes of pollution and self-purification of natural waters. Chisinau: USM Editorial Center, 2002, 145 p. (in Romanian).

[17] Duca, Gh., Mihaila, G., Goreaceva, N., Chetrus, P. Chemistry of natural waters. Chisinau: Moldova State University, 1995, 287 p. (in Romanian).

[18] Gladchi, V. Catalytic transformations and the redox state of the environment: Monograph. Chisinau: CEP USM, 2018, 212 p. (in Romanian).

[19] Duca, G., Scurlatov, Yu. Ecological Chemistry. Chisinau: CE USM, 2002, $289 \mathrm{p}$

[20] Duca, G., Scurlatov, Yu., Sychev, A. Redox catalysis and ecological chemistry. Chisinau: Publishing Centre M.S.U., $2002,316 \mathrm{p}$.

[21] Chu, C., Stamatelatos, D., McNeill, K. Aquatic indirect photochemical transformations of natural peptidic thiols: impact of thiol properties, solution $\mathrm{pH}$, solution salinity and metal ions. Environmental Science: Processes \& Impacts, 2017, 19, pp. 1518-1527. DOI: https://doi.org/10.1039/C7EM00324B

[22] Fahey, R. C. Glutathione analogs in prokaryotes. Biochimica et Biophysica Acta, 2013, 1830 (5), pp. 3182-3198. DOI: 10.1016/j.bbagen.2012.10.006.

[23] Salinas, G, Comini, M. A. Alternative Thiol-Based Redox Systems. Antioxidants Redox Signal, 2018, 28 (6), pp. 407 409. DOI: 10.1089 /ars.2017.7464. 
[24] Sameem, B., Khan, F., Niaz, K. Nonvitamin and Nonmineral Nutritional Supplements. Elsevier, 2019, pp. 53-58. https://doi.org/10.1016/B978-0-12-812491-8.00007-2

[25] Narainsamy, K., Farci, S., Braun, E., Junot, C., CassierChauvat, C., Chauvat, F. Oxidative - stress detoxification and signalling in cyanobacteria: the crucial glutathione synthesis pathway supports the production of ergothioneine and ophthalmate. Molecular Microbiology, 2016, 100 (1), pp. 1524. DOI: https://doi.org/10.1111/mmi.13296.

[26] Fahey, R. C. Novel thiols of prokaryotes. Annu Rev Microbiol, 2001, 55, pp. $333-356$. DOI: 10.1146/annurev.micro.55.1.333.

[27] Schmidt, A. Sulfur metabolism in cyanobacteria. Methods in Enzymology, 1988, 167, pp. 572-583. DOI: https://doi.org/10.1016/0076-6879(88)67065-0.

[28] Giordano, M., Norici, A., Ratti, S., Raven, J. A. Role of Sulfur for Algae: Acquisition, Metabolism, Ecology and Evolution. In: Hell R., Dahl C., Knaff D., Leustek T. (eds) Sulfur Metabolism in Phototrophic Organisms. Advances in Photosynthesis and Respiration, vol 27. Springer: Dordrecht, 2008, pp. 397-415.
[29] Duca, G., Gladchi, V., Goreaceva, N. Practical works on natural water chemistry. Chisinau: CEP USM, 2007, 108p. (in Romanian).

[30] Ellman, G. L. Tissue sulfhydryl groups. Archives of Biochemistry and Biophysics, 1959, 82, pp. 70-77. DOI: 10.1016/0003-9861(59)90090-6.

[31] Riddles, P. W., Blakeley, R. L., Zerner, B. Reassessment of Ellman's reagent. Methods in Enzymology, 1983, vol. 91, pp. 49-60. DOI: https://doi.org/10.1016/S0076-6879(83)91010-8

[32] Boussiba, S., Richmond, A. E. C-phycocyanin as a storage protein in the blue-green alga Spirulina platensis. Arch. Microbiol., 1980, 123, pp. 143-147. DOI: https://doi.org/10.1007/BF00403211

[33] Goreaceva, N., Gladchi, V., Bunduchi, E., Șurighina, O., Romanciuc, L. Analysis of the multiannual dynamics of the ionic composition of the Dniester river waters. Studia Universitatis Moldaviae, Real and Natural Sciences Series, 2011, 1 (41), pp. 161-166. (in Romanian).

[34] Goreaceva, N., Duca, G. Hydrochemistry of small rivers of the Republic of Moldova: Monograph. Chisinau: Publishing Centre M. S. U., 2004, 288 p. (in Russian). 